\title{
PENGARUH ASPEK SOSIAL EKONOMI TERHADAPMOTIVASIPROFESI NELAYAN (STUDI KASUS DI DESA TATELI IIKECAMATAN MANDOLANG KABUPATEN MINAHASA)
}

\author{
Jecky Sasue ${ }^{1}$, Victoria E.N. Manoppo' ${ }^{2}$, Florence V. Longdong ${ }^{2}$ \\ 1)Mahasiswa Fakultas Perikanan dan IImu Kelautan Universitas Sam Ratulangi Manado \\ 2)Staff Pengajar Fakultas Perikanan dan IImu Kelautan Universitas Sam Ratulangi Manado \\ Koresponden email :jeckysasue77@gmail.com
}

\begin{abstract}
The number of fisherman in North Sulawesi Province is reached 93,845 people in 2012. Tateli II village Minahasa regency, Mandolang sub District the social economic condition of fisherman who lived in coastal communities are a group of people are electivity undeveloped if compare. The other communities group, but infect they are happy as a fisherman. Does the profession as a fisherman have a correlation with social economic.

The purpose of this research to study the general situations social economic of fisherman and to concern the information about Social economic aspect in the motivation of fisherman children to work as a fisherman

The method to be used is descriptiveexplorative in case study. The collecting date through two sources primary and secondary date. And date analysis by using descriptive analysis qualitative and quantitative analysis, which measure any effect that fisherman children work as a fisherman are analysis by multiple regression.

The result show that social condition in education, dependent famely, transfer knowledge and skill, and health, where the economic conclusion the income expenditure, capital and tools ownership. It's found that 0,180564 > 0,05weaas the motivations of fisherman children not influence by educations 0,408463>0,05 not influence by dependent $0,06509>0,05$ not influence by income 0,543403 > 0,05 not influence by tool ownership

The conclusion that the motivations of fisherman children to become fisherman are not influence by education, famely dependent income and tools ownership

Keyword: fisherman profession, motivations, Tateli II

\section{Abstrak}

Provinsi Sulawesi Utara, pada tahun 2012 jumlah nelayan mencapai 93.845 orang. Kabupaten Minahasa khususnya di Desa Tateli II Kecamatan Mandolang kondisi sosial ekonomi masyarakat nelayan atau masyarakat pesisir merupakan kelompok masyarakat yang relatif tertinggal secara sosial dan ekonomi dibandingkan dengan kelompok masyarakat lain.

Tujuan penelitian untuk menelaah keadaan umum, sosial dan ekonomi nelayan dan untuk menghitung berapa besar pengaruh aspek sosial ekonomi nelayan menjadi motivasi anak nelayan untuk berprofesi sebagai nelayan.

Penelitian ini menggunakan metode deskriptif eksploratif dan bersifat studi kasus. data yang dikumpulkan melalui dua sumber yaitu data primer dan data sekunderdata primer adalah data yang diperoleh melalui observasi, wawacara langsung dan melakukan pengisisan kuisioner yang terstruktur.

Hasil menunjukkan bahwa keadaan sosial menyangkut tingkat pendidikan, tanggungan keluarga, transfer pengetahuan dan keterampilan, dan kesehatan sedangkan ekonomi menyangkut pendapatan, pengeluaran, modal, dan kepemilikan alat. Setelah dianalisis dengan analisis regresi berganda didapatkan hasil bahwa 0.180564 >0,005 yang berarti motivasi anak nelayan berprofesi sebagai nelayan tidak dipengaruhi oleh pendidikan, $0.408463>0,05$ yang berarti motivasi anak nelayan berprofesi sebagai nelayan tidak dipengaruhi oleh tanggungan keluarga, $0.06539>0,05$ yang berarti motivasi anak nelayan berprofesi sebagai nelayan tidak dipengaruhi oleh pendapatan, $0.543403>0,05$ yang berarti motivasi anak nelayan berprofesi sebagai nelayan tidak dipengaruhi oleh kepemilikan alat.

Kesimpulan bahwa motivasi anak nelayan berprofesi sebagai nelayan tidak dipengaruhi oleh tingkat pendidikan, tanggungan keluarga, pendapatan, dan kepemilikan alat sehingga disarankan agar bisa mengadakan penelitian lanjutan untuk mendapatkan faktor yang signifikan mempengaruhi motivasi anak nelayan berprofesi sebagai nelayan.
\end{abstract}

Kata kunci :Profesi nelayan, Motivasi, Analisis Regresi Berganda, Tateli II 


\section{PENDAHULUAN}

Provinsi Sulawesi Utara, pada tahun 2012 jumlah nelayan mencapai 93.845 orang. Nelayan di Provinsi Sulawesi Utara didominasi di Kabupaten Kepulauan Sangihe, selanjutnya adalah Kota Bitung dan Kabupaten Kepulauan Talaud (Anang, 2013).

Dinas Kelauatan dan Perikanan (DKP) Sulawesi Utara saat ini mencatat ada 33.943 nelayan yang tersebar di 13 kabupaten/kota.Secara Khusus nya di Kabupaten Minahasa pada tahun 2017 mencapai 9.173 orang nelayan.Jumlah ini terdiri atas 4.672 orang nelayan penuh, 2.125 orang nelayan sambilan utama dan sisanya adalah nelayan sambilan tambahan (Dinas Kelautan dan Perikanan Kabupaten Minahasa, 2017).Desa Tateli II yang menjadi obyek penelitian memiliki 40 nelayan.

Kondisi sosial ekonomi masyarakat nelayan atau masyarakat pesisir merupakan kelompok masyarakat yang relatif tertinggal secara sosial dan ekonomi dibandingkan dengan kelompok masyarakat lain. Kondisi masyarakat nelayan atau masyarakat pesisir diberbagai kawasan pada umumnya ditandai oleh adanya beberapa ciri, seperti kemiskinan, keterbelakangan sosial-budaya, rendahnya sumberdaya manusia.sehingga pada saat ini dapat dilihat bahwa sebagian besar masyarakat pesisir masih berada di bawah garis kemiskinan (Nawawi, 2014).

Berdasarkan pengamatan awal jumlah nelayan yang ada di Desa Tateli II kurang lebih 40 orang dengan latar belakang nelayan tradisional.Masyarakat nelayan di Desa ini sangat rajin dan ulet sejak jaman dulu atau sejak jaman kakek atau orang tua mereka.Hal Ini disebabkan karena mereka mendapatkan ketrampilan melaut dari orang tua mereka secara turun temurun dengan kondisi ekonomi yang memadai.

Desa Tateli II yang masih tertinggal secara ekonomi dan sosial. Namun demikian berdasarkan pengamatan awal nelayan Desa Tateli II walaupun mereka berada dalam kondisi ekonomi yang relatif rendah akan tetapi mereka tetap senang berprofesi sebagai nelayan. Namun demikian akan menjadi pertanyaan apakah dengan keadan mereka yang demikian itu bisa memotivasi anak-anak untuk mengikuti jejak ayah mereka berprofesi sebagai nelayan. Untuk itu diperlukan penelitian sehingga mendapatkan informasi tentang pengaruh sosial ekonomi terhadap motivasi profesi sebagai nelayan.

\section{METODE PENELITIAN}

Penelitian ini menggunakan metode studi kasus, menggunakan berbagai sumber data (sebanyak mungkin data) yang bisa digunkan untuk meneliti, menguraikan dan menjelaskan secara komfrensif berbagai aspek individu, kelompok, suatu program, organisasi atau peristiwa secara sistematis di saat penelitian akan menggunakan angket. Angket atau lembaran pertanyaan adalah sebagai alat penelitian yang dilakukan pada populasi besar maupun kecil tetapi data yang dipelajari adalah data dari sampel yang diambil dari populasi tersebut sehingga ditemukan kejadian relative distribusi dan hubungan antar variabel, sosiologis maupun psikologis (Sugiyono, 2013).

Pengambilan sampel menggunakan teknik purposive sampling.yaitu suatu cara pengumpulan data yang sifatnya tidak menyeluruh, yaitu tidak mencakup seluruh objek 
penelitian (populasi) akan tetapi sebagian saja dan secara sengaja diambil dari suatu populasi (Sugiyono, 2014).

Selanjutnya jawaban akan diukur dengan menggunkan skala pengukuran yaitu Skala Likert. Analisis data untuk menjawab tujuan ketiga, menggunakan analisisi regresi linear berganda. Persamaan regresi linear berganda, yaitu :

$Y=a+b 1 X 1+b 2 X 2+b 3 X 3+b 4 X 4+\ldots \ldots+b n X n$

dimana : $Y=$ Motivasi profesi nelayan

Sosial:

$\mathrm{X} 1=$ Pendidikan

X3=Pendapatan

Ekonomi :

$\mathrm{X} 2=$ Tanggungan Keluarga

X4=Kepemilikan Alat

Uji pengaruh secara bersamasama menggunakan statistik uji $\mathrm{F}$ dan uji parsial menggunakan statistik uji t. Signifikansi uji pengaruh mengunakan nilai $P$, yaitu $P<0,05 \rightarrow$ signifikan, dan $P$ $>0,05 \rightarrow$ non signifikan.

Pengaruh Aspek Sosial Ekonomi Terhadap Motivasi Profesi Nelayan, maka hipotesa peneliti sebagai berikut: $\mathrm{HO}=$ Tidak berpengaruh $\mathrm{H} 1=$ Berpengaruh

\section{HASIL DAN PEMBAHASAN}

\section{Transfer Pengatahuan dan Keterampilan}

Pengetahuan dan keterampilan sangat erat kaitan dengan profesi sebagai nelayan. Semakin banyak pengetahuan tentang melaut atau menangkap ikan dan semakin banyak pengetahuan mereka tentang cara menangkap ikan, meningkatkan hasil tangkapan, maka tingkat pendapatan mereka semakin tinggi. Berikut ini Gambar 1: Frekuensi anak mengikuti orang tua melaut nelayan di Desa Tateli Dua:

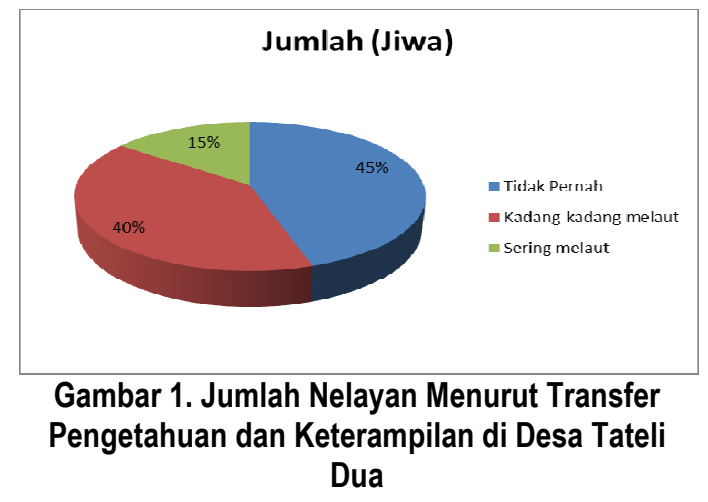

Gambar 1 menunjukan bahwa untuk anak nelayan yang tidak pernah melaut berjumlah 9 orang atau $45 \%$, berdasarkan wawancara dengan 20 responden nelayan perlu diketahui bahwa dari pihak orang tua rata-rata mereka menginginkan anaknya untuk tetap bersekolah menempuh pendidikan setinggi mungkin dengan kata lain para orang tua tidak mau anaknya mengikuti profesi mereka sebagai nelayan sudah menjadi kewajiban orang tua meskipun hanya berprofesi sebagai nelayan diketahui melalui wawancara langsung ada responden bahwa walaupun hanya berprofesi nelayan tetapi dapat menyekolahkan anaknya sampai tamat kuliah. Selanjutnya anak yang kadangkadang melaut berjumlah 8 orang atau $40 \%$ dan yang terakhir anak nelayan yang sering melaut hanya berjumlah 3 orang atau $15 \%$ hal ini disebabkan karena dari pihak orang tua juga sering mengajak anak sepulang sekolah untuk turun melaut dengan alasan guna dapat mengetahui cara dan alat apa saja yang dipakai dalam proses mencari dan menangkap ikan.

\section{Kesehatan}

Kesehatan merupakan salah satu aspek profesi sebagai nelayan, di Desa Tateli Dua dari data 20 responden yang ada diketahui bahwa angka kesehatan penduduk terbilang baik jarang 
mengalami kondisi kesehatan yang serius. Berikut ini Gambar 2 kondisi kesehatan nelayan di Desa Tateli Dua :

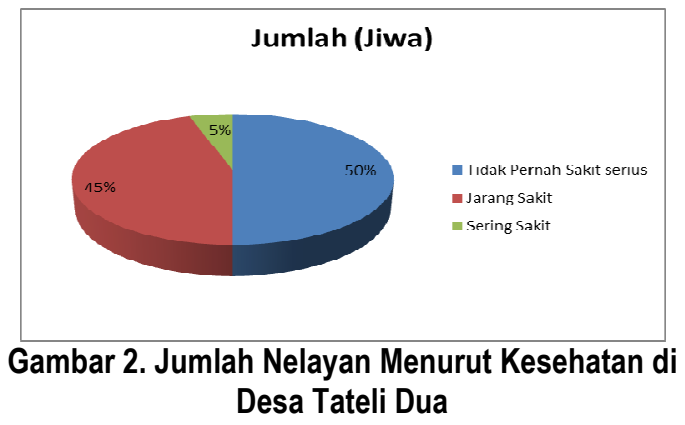

Kondisi kesehatan nelayan yang tidak pernah sakit berjumlah 10 orang atau $50 \%$, Gambar 9 menunjukan bahwa tingkat kesehatan nelayan di Desa Tateli Dua sangat jarang bahkan tidak pernah mengalami kondisi kesehatan yang serius. Berdasarkan wawancara dari data 20 responden yang ada diketahui nelayan hanya mengalami kondisi kesehatan yang ringan seperti flu, demam dan nyeri sendi.Kondisi seperti itu memang sudah menjadi sakit yang biasa dialami oleh nelayan. selanjutnya angka nelayan yang jarang sakit berjumlah 9 orang atau $45 \%$, dan yang terakhir nelayan yang sering sakit berjumlah 1 orang atau $5 \%$ hal ini disebabkan dari faktor umur yang sudah melebihi batas.

\section{Pendapatan}

Rincian tingkat pendapatan nelayan perbulan nya di Desa Tateli Dua disajikan pada Gambar 3.

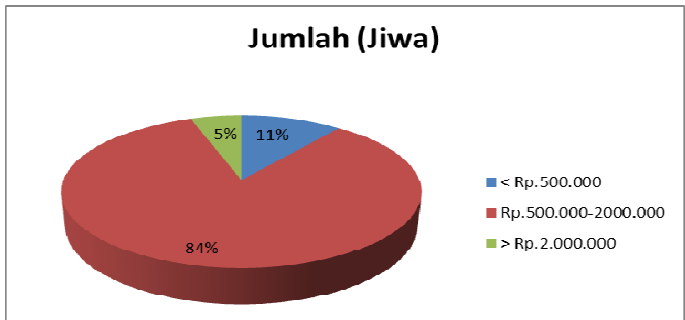

Gambar 3. Jumlah Nelayan Menurut Pendapatan di Desa Tateli Dua
Berdasarkan Gambar 3 pendapatan nelayan yang paling sedikit adalah nelayan perbulan kurang dari $\mathrm{Rp}$. 500.000 berjumlah 2 orang atau $10 \%$, berdasarkan penelitian hal ini karena teknologi alat penangkapan yang masih kurang memadai akibatnya wilayah penangkapan hanya di sekitar pesisir Desa Tateli Dua, yang dapat menyebabkan jumlah tangkapan kurang maksimal sehingga mempengaruhi pendapatan. Selain itu pendapatan utama sebagai seorang nelayan juga dipengaruhi oleh cuaca dimana dalam satu bulan hanya 1-2 minggu melakukan operasi penagkapan.Namun di saat cuaca seperti penduduk nelayan memanfaatkannya untuk melakukan pekerjaan sambilan. Berikut ini pekerjaaan sambilan seperti buruh tani kangkung, buruh dan juga sebagai tukang ojek, sebagian besar pekerjaan sambilan nelayan adalah sebagai buruh tani, ini karena di Desa Tateli Dua terdapat banyak usaha pertanian tanaman kangkung yang luas penggunaan lahannya mencapai 20 ha. Hal ini dimanfaatkan para nelayan guna untuk menambah penghasilan dan bekereja sebagai petani kangkung. Hasil dari pekerjaan sampingan tersebut, ratarata berjumlah Rp. 500.000 per bulan .

\section{Pengeluaran}

Profesi sebagai nelayan sangatlah tidak gampang karena tuntutan biaya pengeluaran yang besar.Diketahui pada waktu penelitian data dari 20 responden bahwa pengeluaran per hari untuk satu keluarga rata-rata berjumlah kurang dari Rp. 100.000. Berikut ini gambar pengeluaran nelayan di Desa Tateli Dua: 


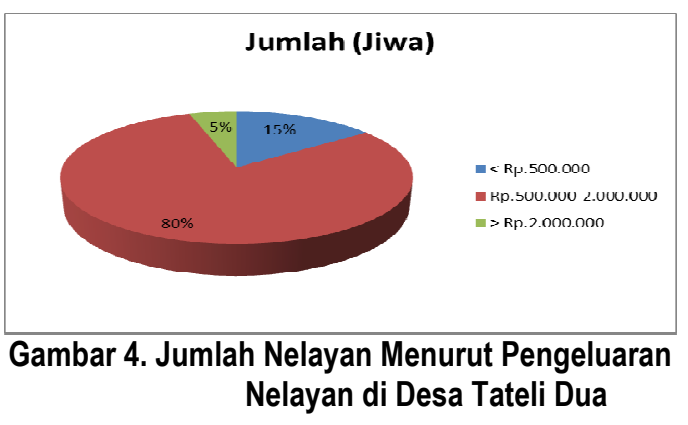

Berdasarkan gambar 4 dapat dilihat pengeluaran kurang dari Rp. 500.000 hanya berjumlah 3 orang atau $15 \%$, selanjutnya pengeluaran nelayan di angka Rp. 500.000 - Rp. 2.000 .000 berjumlah 16 orang atau $80 \%$, dan yang terakhir pendapatan nelayan lebih dari Rp. 2.000 .000 berjumlah 1 orang atau $5 \%$.

\section{Modal}

Modal kerja adalah jumlah dana yang digunakan selama periode tertentu yang dimaksudkan untuk menghasilkan pendapatan jangka pendek (current income) yang sesuai dengan maksud utama memulai usaha. Dalam memulai usahanya, nelayan membutuhkan modal yang cukup untuk menangkap ikan.Adapun modal tersebut dibutuhkan untuk membeli perahu, mesin, alat penangkap ikan, serta alat-alat tambahan yang dapat menunjang untuk meningkatkan hasil tangkapannya (Wahyu, 2011).

Modal usaha yang dikeluarkan nelayan di Desa Tateli Dua dalam menjalankan dan mengembangkan usahanya diperlukan modal, nelayan menggunkan modal sendiri dan modal pinjam yang berasal dari kerabat, saudara atau pun orang tua. Berikut adalah Gambar 4 rincian jumlah modal nelayan di Desa Tateli Dua.

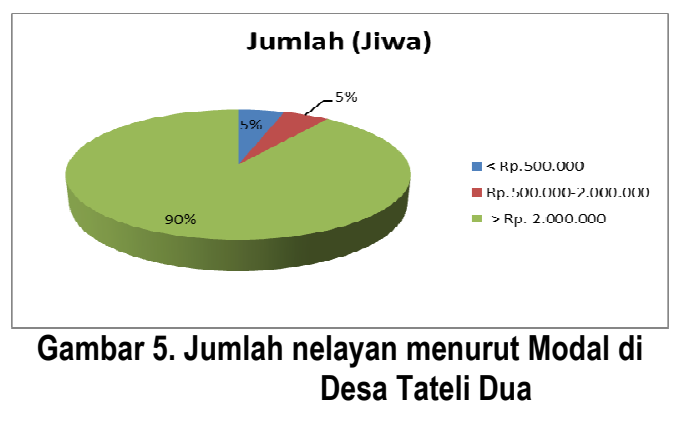

Gambar 5 menunjukan bahwa modal yang dikeluarkan untuk membeli alat tangkap kurang dari Rp. 500.000 berjumlah 1 orang atau $5 \%$, berdasarkan wawancara dengan responden diketahui bahwa modal yang dikeluarkan sedikit karena peralatan yang dimiliki hanya peralatan seadanya seperti perahu katinting yang memakai kekuatan motor sebesar 6 PK, berbeda dengan perahu lainnya yang memakai mesin merek Yamaha 40 PK. Modal yang biasa dikeluarkan diantara Rp. 500.000 - Rp. 2.000 .000 berjumlah 1 orang atau $5 \%$, dan yang terakhir modal yang dikeluarkan nelayan lebih dari Rp. 2000.000 berjumlah 18 orang atau $90 \%$. Dan untuk modal satu kali melaut berdasarkan wawancara dari data 20 responden nelayan yang ada rata-rata berjumlah kurang dari Rp. 500.000 .

\section{Kepemilikan Alat}

Kepemilikan alat tangkap oleh nelayan di Desa Tateli Dua rata-rata semuanya memiliki alat sendiri. Berdasarkan wawancara dengan responden mereka memiliki alat sendiri dengan latar belakang kepemilikan yang berbeda-beda dimana ada alat pemberian dari orang tua, beli sendiri dengan uang pensiunan, dan ada alat dari modal usaha sendiri. Berikut ini adalah Gambar 6 : jumlah kepemilikan alat di Desa Tateli Dua : 


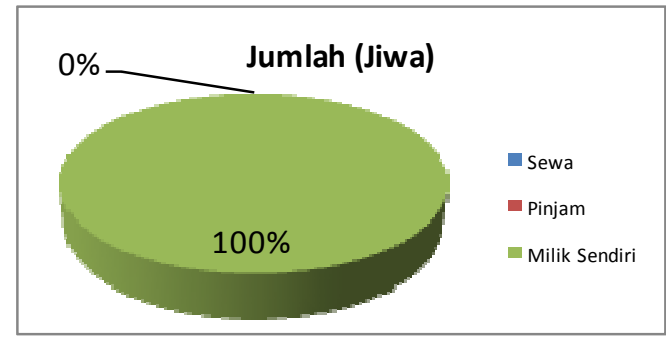

Gambar 6. Jumlah Nelayan Menurut Kepemilikan Alat

Gambar 6 menunjukan bahwa rata-rata di Desa Tateli Dua memiliki alat tangkap sendiri yang berjumlah 20 orang atau $100 \%$, alat yang dimiliki berupa perahu, mesin, jaring, pancing dan tombak ikan.

\section{Faktor-faktor yang Mempengaruhi Profesi Sebagai Nelayan}

Analisis untuk mengetahui faktorfaktor yang mempengaruhi profesi nelayan adalah dengan mengolah datadata menggunakan uji regresi linear berganda. Pengolahan data tersebut menggunakan alat bantu statistik Microsoft Excel yang hasilnya sebagai berikut:

Analisis Pengaruh Faktor $X$ Terhadap Faktor $Y$

Hasil analisis ditunjukkan melalui persamaan

$Y=a+b 1 \times 1+b 2 \times 2+b 3 \times 3+b 4 \times 4+\ldots . .+b n \times n$

$Y=-0,61+0,38 X 1+0,14 X 2+0,71 \times 3-0,14 X 4+e$

Dimana

$Y=$ Motivasi profesi sebagai nelayan

$\mathrm{X} 1$ = Pendidikan

$\mathrm{X} 2$ = Tanggungan Keluarga

X3 = Pendapatan Nelayan

X4 = Kepemilikan Alat

$\mathrm{A}=$ konstanta

Pengaruh Faktor Pendidikan (X1) Terhadap Motivasi Profesi Nelayan

Berdasarkan nilai probabilitas sebesar 0.180564atau lebih besar dari nilai alpha $0,05(5 \%)$ sehingga 0,180564 $>0,05$ yang mengartikan bahwa variabel pendidikan secara parsial berpengaruh tidak signifikan terhadap motivasi profesi nelayan dan pengaruhnya hanya $18 \%$, maksudnya hanya $18 \%$ pengaruh pendidikan terhadap motivasi profesi nelayan. Hal ini jelas dijumpai pada hasil penelitian di lapangan bahwa pendidikan para nelayan di Desa Tateli Dua kebanyakan hanya lulusan Sekolah Dasar (SD) bahkan ada yang tidak sampai tamat SD sehingga mereka memutuskan untuk berprofesi sebagai nelayan hingga saat ini.

\section{Pengaruh Faktor Tanggungan Keluarga (X2) Terhadap Motivasi Profesi Nelayan}

Berdasarkan nilai probabilitas sebesar 0.408463 atau lebih besar dari nilai alpha 0,05 (5\%) sehingga 0.408463 $>0,05$ yang mengartikan bahwa variabel tanggungan keluarga secara parsial berpengaruh kurang signifikan terhadap motivasi profesi nelayan dan pengaruhnya hanya $40 \%$ pada tingkat kesalahan $5 \%$.

Berdasarkan data 20 responden yang ada rata-rata mempunyai tanggungan keluarga yang lebih dari 5 berjumlah 9 orang atau $45 \%$. Sebanyak 8 orang atau $40 \%$ mempunyai tanggungan 3-5, dan sisanya tanggungan kurang dari 3 berjumlah 3 orang atau $15 \%$. Data ini menunjukan bahwa besarnya jumlah anggota keluarga akan memberi dorongan bagi rumah tangga bersangkutan untuk lebih banyak menggali sumber pendapatan lainnya karena semakin banyak anggota rumah tangga cenderung semakin sulit merencanakan memenuhi kebutuhan sehari-hari. Walaupun demikian banyaknya anggota keluarga tidak berpengaruh besar karena mereka merasa mampu untuk menanggung 
semua jumlah keluarga sebanyak itu meski hanya berprofesi sebagai nelayan.

\section{Pengaruh Faktor Pendapatan (X3) Terhadap Motivasi Profesi Nelayan}

Berdasarkan nilai probabilitas sebesar 0.065397 atau lebih besar dari nilai alpha 0,05 (5\%) sehingga 0.065397 $>0,05$ yang mengartikan bahwa variabel pendapatan secara parsial berpengaruh tidak signifikan terhadap motivasi profesi nelayan dan pengaruhnya hanya kecil yaitu sebesar $6 \%$ pada tingkat kesalahan $5 \%$. Maksudnya variabel pendapatan dapat dikatakan bahwa belum memberikan arti dalam hal motivasi profesi nelayan.

\section{Pengaruh Faktor Kepemilikan Alat (X4) Terhadap Motivasi Profesi Nelayan}

Berdasarkan nilai probabilitas sebesar 0.543403 atau lebih besar dari nilai alpha $0,05(5 \%)$ sehingga 0.543403 $>0,05$ yang mengartikan bahwa variabel kepemilikan alat secara parsial berpengaruh agak signifikan terhadap motivasi profesi nelayan dan pengaruh nya hanya sebesar $54 \%$ pada tingkat kesalahan $5 \%$.

Kepemilikan Alat di Desa Tateli Dua berdasarkan penelitian semuanya memiliki alat sendiri dengan latar belakang kepemilikan yang berbedabeda ada yang warisan dari orang tua, modal sendiri dan juga dari hasil pinjam dari kerabat mereka.

\section{Interpretasi Koefisien Regresi}

Berdasarkan hasil analisis regresi didapat persamaan sebagai berikut:

Rumus:

$Y=a+b 1 X 1+b 2 X 2+b 3 X 3+b 4 X 4+\ldots . .+b n X n$ Hasil:

$Y=-0,61+0,38 X 1+0,14 X 2+0,71 X 3-0,14 X 4+e$
Nilai a atau konstanta $=-0.61$ artinya apabila variabel pendidikan, tanggungan keluarga, pendapatan dan kepemilikan alat diasumsikan $=0$, maka motivasi profesi nelayan sebesar 0,61.

Nilai b1 $=0,38$ artinya setiap kenaikan pendidikan sebesar 1 satuan tingkatan maka akan terjadi peningkatan terhadap motivasi anak berprofesi sebagai nelayan sebesar 0,38 dengan asumsi tanggungan keluarga adalah tetap (ceteris paribus) dan faktor-faktor lain juga tetap. Hal ini sesuai dengan pendapat Tarigan dalam penelitian berjudul: Pengaruh Tingkat Pendidikan Terhadap Tingkat Pendapatan yang menyatakan bahwa seseorang yang mempunyai pendidikan tinggi tentunya lebih banyak dibutuhkan dalam masyarakat atau lingkungan kerja dari pada yang berpendidikan rendah.

Nilai $b 2=0,14$ artinya setiap kenaikan tanggungan keluarga meningkat satu orang maka akan terjadi peningkatan terhadap motivasi profesi nelayan sebesar 0,14 dengan asumsi satuan pendapatan adalah tetap (ceteris paribus) dan faktor-faktor lain juga tetap. Hal ini sesuai dengan, (Surroya, 2017) Banyaknya jumlah anggota keluarga (3 5 orang) akan mempengaruhi tinggi rendahnya pendapatan per kapita dan besarnya konsumsi keluarga.

Nilai b3 $=0,71$ artinya jika pendapatan meningkat satu rupiah maka akan terjadi peningkatan terhadap motivasi profesi nelayan sebesar 0,71 satuan dengan asumsi kepemilikan alat adalah tetap (ceteris paribus) dan faktorfaktor lain juga tetap.

Nilai b4 = -0,14 artinya jika kepemilikan alat penurunan satu unit maka akan terjadi penurunan terhadap motivasi profesi nelayan sebesar 0,14 satuan dengan asumsi pendidikan adalah tetap (ceteris paribus) dan faktor- 
faktor lain juga tetap. Hal ini sesuai dengan, (Siregar, 2016) dengan kesederhanaan alat tangkap yang dimiliki pada musim tertentu tidak ada tangkapan yang dapat diperoleh.

\section{KESIMPULAN}

Desa Tateli Dua terletak di Kecamatan Mandolang Kabupaten Minahasa Provinsi Sulawesi Utara dengan luas daerah sebesar 429.000 ha dimana mata pencaharian adalah: nelayan $3 \%$, tukang $10 \%$, PNS $16 \%$, sopir dan ojek $2 \%$, peternak $10 \%$, petani $14 \%$, dan yang terbanyak adalah bekerja di sektor swasta sebesar $24 \%$.

Aspek-aspek sosial ekonomi nelayan di Desa Tateli Dua adalah sebagai berikut: aspek sosial diantaranya adalah tingkat pendidikan dan tanggungan keluarga dan aspek ekonomi diantaranya adalah pendapatan nelayan dan kepemilikan alat.I

Aspek-aspek sosial ekonomi yang tidak berpengaruh secara signifikan terhadap motivasi profesi; dimana tingkat pendidikan $0,180564>0,05$, tanggungan keluarga $0.408463>0,05$, pendapatan $0.065397>0,05$, dan kepemilikan alat $0.543403>0,05$.

Berdasarkan hasil penelitian dari keempat variabel yang ada tidak berpengaruh terhadap motivasi profesi nelayan, karena para orang tua nelayan ingin anaknya tetap bersekolah dan tidak ingin anaknya mengikuti profesi mereka sebagai nelayan.

\section{DAFTAR PUSTAKA}

Adhar, 2012. Analisis Faktor-faktor yang Mempengaruhi Tingkat Pendapatan Usaha Nelayan di Kabupaten Bone. Skripsi. Jurusan IImu Ekonomi Fakultas Ekonomi dan Bisnis Universitas Hasanuddin Maksasar.

Arikunto, S., 2010. Prosedur Penelitian Suatu Pendekatan Praktek. Jakarta: Rineka Cipta.
Aswan, T., Manoppo, V. E. N., dan Mantiri, D. M. H., 2013. Study of Sangihe-Filipino Fishermen Activity in Bitung City North Sulawesi Indonesia. Jurnal IImu dan Manajemen Perairan vol. 1 No. 2 Tahun 2013.

Dewi, I., dan Rustariyuni, S., 2013. Analisis Faktorfaktor Yang Mempengaruhi Nelayan Buruh di Sepanjang Muara Sungai ljo Gading Kabupaten Jemranah. Jurnal Ekonomi Pembangunan. Vol. 3No. 1

Diata, N., Manoppo, E. N. V. dan Durand, S. S., 2018. Peran Perempuan Terhadap Rumah Tangga Nelayan Buruh Yang Beraktivitas di Tempat Pelelangan Ikan (TPI) Tilamuta, Kabupaten Boalemo. Jurnal Akulturasi Vol. 6 No. 11 (April 2018). ISSN 23374195.

Dwiandra, A., 2013. Pengaruh Umur, Pendidikan, Pekerjaan Terhadap Pendapatan Rumah Tangga Miskin di Desa Bebandem. E-Jurnal Ekonomi Pembangunan Universitas Udayana., 2 (4): 173180

Fergiyono, N., 2013. Teori-teori Motivasi. Grasindo, Jakarta.

Hamdani, H., 2013. Faktor Penyebab Kemiskinan Nelayan (The Factor of Poverty Causes Traditional Fisherman). Artikel IImu Kesejahteraan Sosial Fakultas IImu Sosial dan Ilmu Politik Universitas Jember (UNEJ).

Hendratmoko, C., 2010. Analisis Tingkat Keberdayaan Sosial Ekonomi Nelayan Tangkap di Kabupaten Cilacap. STIE. Surakarta. Jurnal Agriva Unibraw, 1(1): 1-2.

Husein, U., 2010. Studi Kelayakan Bisnis. Jakarta: Gramedia Pustaka Utama.

Imron, A., 2012. Strategi dan Usaha Peningkatan Kesejahteraan Hidup Nelayan Tanggul Sari Mangunharjo Tugu Semarang Dalam Menghadapi Perubahan Iklim. Jurnal Riptek Vol 6 No 1.

Kementrian Kelautan Perikanan Direktorat Jendral Perikanan Tangkap. 2011. Statistik Perikanan Tangkap Indonesia. (PKBM) Carabaca Makassar.

Lewis, B. K., (2010). Social Media and Strategic Communication: Attitudes and Perceptions Among College Student. International Journal of Public Relation Society of America.

Manoppo, V. E. N., 2017. IBM Kelompok Nelayan Desa Tateli III Kecamatan Mandolang Kabupaten Minahasa dalam Menerapkan Sistem Rantai Dingin Guna Meningkatkan Pemasaran dan Pendapatan. (online), http://ejournal. unsrat. ac. id/index. php/akulturasi. Diakses tanggal 27 Agustus 2018. 
Mubarok, A. F., 2011. Analisis Pendapatan dan Strategi Pemenuhan Kebutuhan Ekonomi Masyarakat Nelayan Pandega di Kecamatan Kedung Kabupaten Jepara. Skripsi. Fakultas Ekonomi Universitas Semarang.

Muflikhati, I., dkk. 2010. Kondisi Sosial Ekonomi dan Tingkat Kesejahteraan Keluarga Kasus di Wilayah Pesisir Jawa Barat. Jurnal IImu Keluarga. \& Konsumsi, Volume 3, No 1, 1-10.

Nawawi, M. N., 2018. Sosial Ekonomi Masyarakat Pesisir. Yogyakarta.

Paulus, C., 2011. Gambaran Umum Wilayah Pesisir Indonesia. http://chaterinapaulus. blogspot. com/gambar. Diakses 29 Agustus 2018.

Rahman, R., 2016. Pengaruh Modal, Tenaga Kerja dan Jarak Tempuh Melaut Terhadap Pendapatan Nelayan di Desa Pulau Kaung Kecamatan Buer. Fakultas Ekonomi \& Manajemen Universitas Samawa Program Studi Ekonomi Pembangunan ISSN (P) : 2089-1210, E-ISSN: 2580-7285 Jurnal Ekonomi dan Bisnis Vol 14 No 2.

Retnowati, E., 2011. Nelayan Indonesia dalam Pusaran Kemiskinan Struktural (Prespektif Sosial, Ekonomi, dan Hukum). Jurnal Prespektif Volume 16 Nomor 5.

Rosyidi, S., 2011. Pengantar Teori Ekonomi Pendekatan Kepada Teori Ekonomi Mikro \& Makro. Jakarta: Rajagrafindo persada.

Sadili, S., 2010. Manajemen Sumber Daya Manusia. Bandung: CV. Pustaka Setia.

Santoso S., 2012. Kesehatan dan Gizi. Jakarta Rineka Cipta.

Sastrawidjaya. 2002. Nelayan Nusantara. Pusat Riset Pengolahan Produk Sosial Ekonomi Kelautan dan Perikanan. Jakarta.
Siregar, S., 2016. Kesadaran Masyarakat Nelayan terhadap Pendidikan Anak. Jurnal IImu Pemerintahan dan Sosial Politik 4 (1) (2016): 110.

Sugiyono, 2013. Metodelogi Penelitian Kuantitatif, Kualitatif dan R\&D. (Bandung: ALFABETA)

Sugiyono, 2014. Metode Penelitian Kuantitatif, Kualitatif dan R\&D. Bandung: Penerbit Alfabeta.

Sujarno, 2008. Analisis Faktor-faktor Yang Mempengaruhi Pendapatan Nelayan di Kabupaten Langkat. Thesis. Program Studi Pembangunan Sekolah Pascasarjana Universitas Negeri Medan.

Sumarsono, S., 2003. Ekonomi Manajemen Sumber Daya Manusia dan Ketenagakerjaan. Yogyakarta : Graha Ilmu.

Supardi, M.D., 2006. Metodologi Penelitian. Mataram: Yayasan Cerdas Press.

Suroyya, A.N., 2017. Analisis Ekonomi Rumah Tangga Nelayan Pada Alat Tangkap Gill Net di PPP Morodemak, Kabupaten Demak. Journal of Fisheries Resources Utilization Management and Technology Volume 6, Nomor 4, Tahun 2017, HIm 30-39 Online di: http://www. ejournal-s1. undip ac. id/index. php/ffrumt.

Tarigan, R., 2006. Pengaruh Tingkat Pendidikan Terhadap Tingkat Pendapatan Perbandingan Antara Empat Hasil Penelitian. Jurnal Wawasan, Februari 2006, Volume 11, Nomor 3.

Tarigan, S., E., 2009. Analisis Pekerjaan Alternatif Nelayan Kecamatan Talawi Kabupaten Batu Bara (Studi Kasus: Desa Majid Lama Kecamatan Talawi Kabupaten Batu Bara). Skripsi. Departemen Agribisnis Fakultas Pertanian Universitas Sumatra Utara Medan.

Walgito, G., 2010. Metodologi Penelitian. Grasindo, Jakarta. 